\title{
Mal de arquivo - Um desafio para a filosofia da educação?
}

\section{Archive Fever - A Challenge to the Philosophy of Education?}

\author{
Amarildo Luiz Trevisan* \\ Maurício Cristiano de Azevedo** \\ Geraldo Antonio da Rosa**
}

\begin{abstract}
RESUMO
A partir da reflexão extraída do livro "Mal de arquivo: uma impressão freudiana", de Jaques Derrida, o artigo pretende investigar as consequências da metáfora de "mal de arquivo" para o campo da filosofia da educação. Por intermédio da crença de que a tradição do reprimido se inscreve na ideia de arquivo, procura potencializar o termo para interpretar alguns problemas existentes no campo da relação entre filosofia e educação. Especialmente, dirige o olhar para a forma como surge o discurso da filosofia, bem como a dinâmica cultural que persiste em seguir certas orientações, sua autoridade e a sua genealogia bastante presente no âmbito acadêmico contemporâneo. A desconstrução da metafísica se soma ao trabalho da psicanálise, fazendo o proibido aflorar à consciência, e, portanto, ao nível literal da escritura. E assim, o acontecimento da compreensão pode auxiliar a desmobilizar a compulsão à repetição que se instaurou no arquivo.
\end{abstract}

Palavras-chave: Mal de arquivo. Filosofia da educação. Hermenêutica.

${ }^{*}$ Universidade Federal de Santa Maria. Santa Maria, Rio Grande do Sul, Brasil. E-mail: trevisanamarildo@gmail.com - https://orcid.org/0000-0002-3575-4369

${ }^{* *}$ Instituto Federal Farroupilha. Santo Augusto, Rio Grande do Sul, Brasil. E-mail: mcazevedo.br@gmail.com - https://orcid.org/0000-0003-3309-4499

${ }^{* * *}$ Universidade de Caxias do Sul. Caxias do Sul. Rio Grande do Sul, Brasil. E-mail: geraldorosa06@gmail.com - https://orcid.org/0000-0002-1193-7910 


\begin{abstract}
From the reflection extracted of the book Archive Fever: A Freudian Impression, by Jaques Derrida, the article intends to investigate the consequences of the metaphor of "archive fever" for the field of the philosophy of education. Through the belief that the tradition of the repressed is part of the idea of archive, it seeks to leverage the term to interpret some existing problems in the field of the relation between philosophy and education. In particular, it looks at the way in which the discourse of philosophy emerges, as well as the cultural dynamics that persist in following certain orientations, their authority and their genealogy quite present in the contemporary academic sphere. The deconstruction of metaphysics adds to the work of psychoanalysis, making the forbidden to come to consciousness, and therefore to the literal level of writing. And so, the event of understanding can help to demobilize the compulsion to repetition that has arisen in the archive.
\end{abstract}

Keywords: Archive fever. Philosophy of education. Hermeneutics.

\title{
Considerações iniciais
}

O texto a seguir pretende discutir a expressão "mal de arquivo" no espectro da filosofia da educação. Derrida (2001) apresenta essa reflexão baseado na interpretação do último grande livro de Freud (2018) "O homem Moisés e a religião monoteísta". O livro de Freud gerou uma polêmica recentemente, na qual estiveram envolvidos vários filósofos e historiadores importantes, como foi o caso de Yosef Yerushalmi (1992), "O Moisés de Freud: judaísmo terminável e interminável"; Jan Assmann (1998), em "Moisés, o egípcio", e o próprio Jaques Derrida (2001), "Mal de arquivo. Uma impressão freudiana". ${ }^{1}$ Derrida retorna ao mundo grego para explicar a origem do conceito relacionado à palavra grega arkhê, que significa o começo ou comando ligado a poder e também designa o ambiente onde ficavam os arcontes, os responsáveis por guardar um documento e, ao mesmo tempo, desenvolver a capacidade de interpretá-lo. Eles eram os guardiões de um segredo que não poderia ser revelado ordinariamente, mas para aqueles que se dispunham a percorrer um caminho de preparação e ascese espiritual.

$1 \mathrm{O}$ mencionado livro de Derrida é fruto de conferência dada em Londres pelo autor em junho de 1994, com o título "O conceito de arquivo. Uma impressão freudiana", o qual depois foi modificado no livro publicado na França em 1995. 
No livro, ele discute, entre outros temas, se a psicanálise não seria uma ciência judaica, acusação essa feita pelos nazistas. E, ao fazer uma espécie de rememoração dos arquivos da psicanálise, tendo como fio condutor o livro de Yerushalmi (2001, p. 119) sobre Freud, acaba concluindo algo bastante peculiar, quando diz: "Ora, o princípio da divisão interna do gesto freudiano e, portanto, do conceito freudiano do arquivo é que no momento em que a psicanálise formaliza as condições do mal de arquivo e do arquivo ele próprio, repete a mesma coisa à qual resiste ou que faz de objeto". Ou seja, ao buscar a origem do reprimido, por intermédio das escavações arqueológicas do inconsciente, a psicanálise repete a impressão freudiana (e judaica) de querer "dirigir-se (...) com um gesto compulsivo, repetitivo e nostálgico, um desejo irreprimível de retorno à origem, uma dor da pátria, uma saudade de casa, uma nostalgia do retorno ao lugar mais arcaico do começo absoluto" (YERUSHALMI, 2001, p. 118). Parece que resolver a problemática da diáspora judaica, reencenando a relação entre seu maior patriarca e a tradição que ele funda, é o derradeiro gesto teórico de Freud, sua última inventiva para tratar do problema da violência originária como ato fundante da cultura e de seus dispositivos, enfrentando já a esta altura o terror do antissemitismo. Com isso ele revela o violento ato parricida que retorna incessantemente dentro da própria cultura civilizatória e que se constitui como ato genético e remissivo do arquivo psicanalítico.

A importância dessa discussão é destacada pelo filósofo norte-americano Richard Bernstein (2000, p. 81), quando diz que: "Precisamos cavar mais fundo e descobrir o que Derrida chama de 'o arquivo psicanalítico' e os traços de memórias inconscientes". Tal é a tarefa que aqui buscamos, pois, embora haja um foco do problema na psicanálise, Derrida diz que essa discussão pode ser estendida também para compreender outros campos ou áreas do conhecimento, como a história. Poderíamos aqui fazer muitas ilações, mas de todo modo perguntamos: não é este também um dos grandes problemas da filosofia da educação, alimentado, continuamente, pelo desejo de voltar à sua origem (à sua casa) na filosofia?

Mais do que fazer a psicanálise do campo da filosofia da educação, o objetivo é abrir os seus arquivos, a sua "caixa preta", ou, especialmente, o seu mal de arquivo, para trazer um pouco de luz aos tempos hipersombrios que se impõem no presente. Dessa maneira, move esta empreitada, em um primeiro momento, tomar a leitura de Derrida sobre Freud para pensar o que ele anuncia como "mal de arquivo" na psicanálise. A seguir, abordar à luz dessa discussão alguns problemas que, porventura, existem nesse sentido no âmbito da filosofia e que contribuíram para a autocompreensão do campo da 
Filosofia da Educação. Por fim, como o arquivo também contempla a ideia de promessa, faremos algumas inventivas, no sentido de abrir portas para o futuro da relação filosofia e educação, incorporando os apontamentos realizados a partir da hermenêutica das tradições.

\section{A técnica do arquivamento na psicanálise}

A filosofia e a psicanálise têm uma longa tradição em conjunto. Embora a última tenha nascido somente no início do século XX, a partir da obra de Freud, "A interpretação dos sonhos", ambas comungam do mesmo espírito hermenêutico de volta frequente às origens para encontrar ou renovar os fundamentos da sua ação. Se a filosofia procurou inspiração nos mitos e nas tragédias em busca do senso racional de medida do humano, a psicanálise busca nas mesmas fontes a equação para equilibrar os sentimentos ou afetos esquecidos no tempo. Ou seja, trata-se não de abordagens conflitantes, mas complementares em certo sentido. Por isso, Paul Ricoeur se dispôs a encontrar correlação entre esses dois campos, na obra de "Freud: uma interpretação da cultura", ao debater "as relações entre uma hermenêutica dos símbolos e uma filosofia da reflexão concreta" (RICOEUR, 1990, p. 2, tradução nossa).

É nesse contexto que surge a preocupação freudiana com o problema do arquivo, que remete às suas origens na versão clássica da antiga Grécia, quando o arquivo, enquanto arkhê, se tornava depositário da materialidade ou positividade de um documento. Constituía-se, ontologicamente, como algo fixo e estático e por isso era entendido como um monumento. Por muito tempo a psicanálise de Freud buscou evidências materiais para o arquivo, trabalhando com um conceito metafísico, mas ao mesmo tempo cultivando uma ponta de preocupação positivista pela sua existência material.

O livro "O homem Moisés e a religião monoteista" é relevante porque inaugura uma outra relação com o arquivo, uma vez que Freud chegou a enunciar que ele era um "romance histórico" (DERRIDA, 2001, p. 15). Ou seja, não se trata mais de buscar um suporte ou "verdade material" para os fatos, mas aquilo que o pai da psicanálise chama de "verdade histórica". Embora a metáfora predominante utilizada por ele para explicar o trabalho da terapia seja a da arqueologia, provavelmente deu-se conta aí de que não poderia deixar a psicanálise prisioneira de fontes do passado. E por isso, nessa obra polêmica, ele procura avançar o conceito de arquivo para a dimensão da ficção, da promessa e do futuro. 
No entanto, distante da fundação da psicanálise, e tendo contemplado os horrores do genocídio da segunda guerra - o mal radical -, Derrida vai lançar mão do conceito de "mal de arquivo" para interpretar os esquecimentos e a dimensão de finitude do arquivo, como uma condição para o seu vir-a-ser constante. Nessa nova metáfora, desempenha papel fundamental à noção de pulsão de morte ou de destruição (tânatos), a pulsão que desune ou agride, exercendo esse trabalho aniquilador do arquivo, deixando nele muitas arestas ou lacunas a ser preenchidas.

Ela trabalha para destruir o arquivo: com a condição de apagar mas também com vistas a apagar seus "próprios" traços - que já não podem desde então ser chamados "próprios". Ela devora seu arquivo, antes mesmo de tê-lo produzido externamente. Esta pulsão, portanto, parece não apenas anárquica, anarcôntica (não nos esqueçamos que a pulsão de morte, por mais originária que seja, não é um princípio, como o são o princípio do prazer e o princípio de realidade): a pulsão de morte é, acima de tudo, anarquivica, poderíamos dizer, arquiviolítica. Sempre foi, por vocação, silenciosa, destruidora do arquivo (DERRIDA, 2001, p. 21, grifos do autor).

A compulsão à repetição está presa à pulsão necrófila e, portanto, à destruição do arquivo, o que institucionaliza o mal de arquivo no coração do monumento. Mas como adverte Almeida, "quando o princípio de constância começa a reinar sobre a vida, ameaçando conduzi-la à morte, irrompe improvisadamente Eros, introduzindo novas tensões e, deste modo, perturbando o abaixamento do nível da libido" (ALMEIDA, 2007, p. 229). Desse modo, o arquivo tanto pode ser o lugar de tânatos, da pulsão de morte e destruição, como o lugar de eros, de reunião e consignação, assim como a circuncisão foi um símbolo para os judeus (SOLIS, 2014, p. 382). Dessa forma, abrem-se novas possibilidades para o arquivo, pois ele não fica condicionado apenas ao seu aspecto da reprodução: "Assim, o intérprete, como arquivista que é, fundamentalmente não deve apenas acolher a repetição que insiste no arquivo, mas também relançá-la em direção ao futuro" (BIRMAN, 2008, p. 116).

Contra a versão que o analisa como algo sem rasuras ou lacunas, "uma massa documental fixa e congelada, tendo no registro do passado a sua única referência temporal" (BIRMAN, 2008, p. 109), é preciso interpretar a diferença dos silêncios e dos esquecimentos, do lacunar, sintomático e descontínuo provocados pelo mal de arquivo. Surge daí a superação da metafísica aristotélica do ato e da potência, pois a potência da virtualidade lhe confere uma dimensão 
de ato e, portanto, de presente. Na tripla direção do presente passado, presente atual e presente futuro, denota-se a abertura ou disponibilidade para o seu vir-a-ser frequente. É essa outra dimensão que abre o arquivo para a instância metafórica, poética e da ficção, não subordinada exclusivamente às dimensões do conceito de verdade. Logo, se o inconsciente é uma escrita, consequentemente é, também, um arquivo constituído de lapsos, atos falhos e chistes, além, é claro, de ser permeado por fantasmas que preenchem os interstícios do psiquismo. O inconsciente é a casa dos fantasmas e isso é produzido pela pulsão de morte, que apaga os traços e marcas do arquivo, produzindo o seu avesso - o mal de arquivo. Haveria então trocas discursivas entre repressão e recalque com o retorno do proibido, frente e verso de um mesmo arquivo composto de materialidade e virtualidade. Por isso, ele não se submete apenas à verdade material, mas contempla, fundamentalmente, uma verdade histórica, nos termos de Freud. Desse modo, surge para Derrida uma nova definição de arquivo:

O arquivo não é mais, então, uma memória ontológica que registra um começo e data uma história, não é apenas monológico, refere-se ao nomos, a uma ordem, ao comando que regula, por exemplo, as instituições. Movimenta-se, sim, por uma pulsão arquiviolística. Esse é um dos sentidos da expressão mal de arquivo (SOLIS, 2014, p. 381).

$\mathrm{O}$ arquivo deixa de ser algo da alçada da rememoração e do passado, abandonando a herança de simples conceito metafísico, para ser uma noção, algo aberto, um quase-conceito. É nesse espaço que Derrida vai pensar a impressão freudiana deixada em "O homem Moisés e a religião monoteísta", posto que algumas de suas teses não encontram assento na historiografia tradicional. Primeiramente seria importante uma palavra sobre o método filosófico da desconstrução adotado por Derrida. Os dois livros-chave para entender o método derridiano da desconstrução são: "Gramatologia" e "A escritura e a diferença". Neles, o autor se preocupa em desmontar o discurso da metafísica ocidental baseada na verticalidade e na oposição de pares de conceitos como, entre outros: aparência e essência, dentro e fora, cultura e natureza, presença e ausência, ou fala e escrita. Esses conceitos, alicerçados em binarismos seculares, não escondem o jogo de forças em que a supremacia de um sobre o outro é a regra. Seu método consiste em buscar categorias que resistam às oposições da filosofia clássica, como a noção de espectralidade, que será enfocada mais adiante, e mal de arquivo, a fim de desmontar o discurso metafísico por dentro. 
A hermenêutica desconstrutiva de Derrida questiona nesse sentido primeiramente o suporte do arquivo presente no costume judaico da circuncisão, ao qual Freud obviamente está submetido, e na tipografia, ou seja, no ambiente externo. Diferente da circuncisão que deixava a sua marca de forma íntima, a tipografia é um ambiente técnico exterior, como a lógica do Bloco mágico ${ }^{2}$, um brinquedo de criança utilizado por Freud para tentar explicar o funcionamento do aparelho psíquico. $O$ filósofo francês depreende que a marca da circuncisão na obra freudiana está consoante a sua defesa do patriarcado. Ao mesmo tempo, indaga até que ponto o modelo do Bloco mágico se sustenta diante da evolução técnico-científica do arquivo hoje, diante da revolução da microeletrônica, da informática e a computação. Propõe, desse modo, repensar o próprio arquivamento da psicanálise em atas, cartas, os processos públicos e privados, entre outros, o que a configura dentro de um marco tecnológico específico da época em que foi gestada.

De posse dessas reflexões, Derrida pode questionar ainda a interpretação materialista de Freud proposta pelo grande historiador do judaísmo Yosef Yerushalmi, na medida em que este, ao final do seu livro, constrói um diálogo imaginário com Freud, tentando convencê-lo de que ele é ainda um judeu. De outro modo, Derrida compreende a tese freudiana do Moisés egípcio, pois a sua admissão pela diferença em relação ao judaísmo acaba quebrando a tensão entre um "nós" e um "eles", proposta pela ideologia ariana. Para ilustrar melhor a sua posição, dá como exemplo a passagem bíblica que narra a tentativa de assassinato do profeta Moisés pelos israelitas. Freud havia defendido em seu livro que houve, na verdade, dois Moisés, pois o primeiro teria sido morto pelos seus companheiros descontentes com a forma como ele conduzia o êxodo do povo eleito no deserto. E o segundo teria sido mais bem sucedido, ao conduzir o povo hebreu até a terra prometida. Embora os hebreus tenham tentado matar Moisés, Yerushalmi argumenta, contra Freud, que isso não havia ocorrido realmente, ou seja, tal fato não ficou impresso no arquivo da Escritura Sagrada. Yerushalmi baseia o seu ponto de vista no relato do Livro de Números 14: 10 da Bíblia, que conta haver uma nuvem (da glória de Deus) que interceptava as pedras jogadas pelos israelitas contra o patriarca do judaísmo. No entanto, o filósofo francês contesta essa versão, dizendo que a operação foi realizada, as pedras foram lançadas e, portanto, houve a intenção de matar com a passagem

2 Freud apresentou a reflexão sobre o Bloco mágico no Cap. III de "O mal-estar na civilização" e desenvolveu-a de forma mais detalhada num pequeno texto incluído no livro "O Ego o Id e outros trabalhos" (1923-1925), publicado na edição brasileira standard das obras psicológicas completas de Sigmund Freud. 
ao ato. E que do ponto de vista do inconsciente, isso não faz diferença, uma vez que ele não discrimina a intenção da ação efetivamente realizada. Desse modo, conclui: "Se Moisés não foi assassinado, foi graças a Deus. Deixados a si mesmos, os israelitas, que queriam matar Moisés, o teriam feito: fizeram tudo para matá-lo" (DERRIDA, 2001, p. 86). Portanto, a verdade histórica se impõe sobre a verdade material, pois a ausência da positividade do fato, derivada do mal de arquivo, necessita preencher a lacuna com a interpretação. Assim ele livra Freud das mãos de Yerushalmi que lhe propunha, de certo modo, uma segunda circuncisão (psicológica) ao costume judaico. ${ }^{3}$

A quebra da barreira de um pseudorretorno à origem judaica abre espaços para a compreensão da existência de dois Moisés, que repete a morte do pai original pelo bando primitivo, sendo que a religião (judaica) surge para expiar a culpa por esse assassinato. No caso do cristianismo, há uma reedição dessa violência original com a morte e ressurreição de Cristo. No entanto, como bem assinala Derrida:

Em todos os casos, não haveria porvir sem repetição. E daí, talvez, diria Freud (essa seria portanto a sua tese), não haverá porvir sem o fantasma da violência edipiana que inscreve a sobrerrepressão na instituição arcôntica do arquivo, na posição, a autoposição com a heteroposição do Um e do Único na arkhê monológica. E a pulsão de morte. Sem este mal, que é também o mal de arquivo, o desejo e o problema do arquivo, não haveria sem designação nem consignação (DERRIDA, 2001, p. 102).

Em consequência, por trás da ressurreição de Cristo está a verdade histórica, pois ele era a encarnação do Moisés ressuscitado, que, por sua vez, ocupa o lugar do pai originário da horda primitiva que foi sacrificado pelos filhos, dando abertura assim à democracia. E de tal modo, um após o outro, vão ocupando, enquanto Filho, o lugar de autoridade do Pai, pois a verdade material destruída, recalcada ou reprimida resiste e retorna, podendo ser de maneira física, como também pelo delírio, a loucura e a obsessão, conclui Derrida.

3 Mesmo que Yerushalmi (1992, p. 19) tenta deixar claro logo no início do seu "O Moisés de Freud", que o livro não pretende explorar a identidade judaica de Freud e que o seu interesse no tema é apenas na medida em que o auxilia a interpretar o significado dessa obra freudiana, no entanto a sua insistência no tema, buscando ramificações inclusive na vida do autor, é notória. 
Contudo, segundo Birman (2008, p. 119), o discurso freudiano não se descolou dos pressupostos clássicos da leitura do arquivo, ficando limitado, em última análise, a encontrar uma ordenação real que fosse constitutiva da origem (impressão originária) e da ideia do psiquismo como arquivo. Com isso, não radicalizou o seu achado da verdade histórica de Moisés, procurando um assento ainda na materialidade do fenômeno. É no sentido oposto que Derrida vai mobilizar o desenvolvimento do discurso da psicanálise, insistindo na ideia de que "o arquivo seria da ordem da metáfora e da ficção, isto é, seria permeado por fantasmas e pela espectralidade, permeariam as suas marcas e traços no processo infinito e insistente de produção do diferir e da diferença" ${ }^{4}$ (BIRMAN, 2008, p. 119). Para Meneses (2013), a desconstrução seria uma forma anárquica (an-arkhê), subterrânea, de tradução e recepção da metáfora, capaz de neutralizar o trabalho do negativo que levaria, em tese, segundo a filosofia hegeliana, em direção ao saber absoluto.

\section{O mal de arquivo na Filosofia da Educação}

Fizemos até o momento uma breve reconstrução do sentido da noção de mal de arquivo a partir da controvérsia provocada pela obra "O homem Moisés e a religião monoteísta", de Freud. Percebemos que há uma reencenação histórica de uma violência originária, que explicaria o surgimento da religião e também, de certa forma, da própria ideia de cultura do ponto de vista da psicanálise. Inicialmente estabelecemos um paralelo entre o conceito de arquivo na compreensão da psicanálise freudiana e mal de arquivo, conforme a proposta de Derrida. A analogia é permeada pela relação entre psicanálise e filosofia, na qual a religião faz o papel de termo médio. Pela metáfora de mal de arquivo, a interpretação derridiana mostra como Freud revela o elemento violento na religião-psicanálise (os seguidores matam o pai-fundador e em seu lugar põem

4 Ver a esse respeito a entrevista concedida por Derrida ao Caderno Mais, da Folha de São Paulo, em 26/06/1994, que explica o significado de espectralidade como uma noção de resistência às oposições da metafísica tradicional, a qual ele denomina de "metafísica da presença", pois não se enquadra na dimensão sensível e nem inteligível e por isso serve de estratégia para a desconstrução (DERRIDA, 1994). A espectralidade é a impressão fantasmal, assim como Yerushalmi faz reviver, no final do seu livro, ao interrogar o Freud morto, embora como fantasma não tem como lhe responder, mas como psicanalista devesse permanecer na escuta em silêncio. $\mathrm{O}$ arquivo do inconsciente é povoado de espectros, ou seja, de fantasmas que não dispõem de qualquer objetividade, posto que perderam a sua dimensão ontológica (SOLIS, 2014). 
outro, lidando como uma culpa que se instala na própria cultura). Mas como se dá isso na filosofia da educação, entre filosofia e educação? Como seria essa nostalgia no pensamento da educação?

A filosofia da educação nasce do seio que dá origem à filosofia e reflete sobre os modelos de pensamento constituídos, historicamente, de um ponto de vista filosófico e pedagógico ao mesmo tempo. Traça os diferentes inventários e esquemas de trabalho que os grandes expoentes do pensamento filosófico propuseram como novas formas de compreender o fenômeno educativo, o bem ensinar e o aprender. Desse modo, procura abordar a correlação entre as diferentes formas de encarar o processo pedagógico ao longo da história e a sua estruturação nos sistemas de ensino.

No entanto, os arquivos que a filosofia da educação apresenta nem sempre contemplam as realidades conforme ocorreram, pois o "mal de arquivo" faz parte igualmente da sua história, silenciando algumas iniciativas em prol de outras. Um exemplo é a morte de Sócrates. Segundo define Werner Jaeger, no clássico "Paidéia: a formação do homem grego": "Sócrates é o mais espantoso fenômeno pedagógico da história do Ocidente" (JAEGER, 1995, p. 512). Ele está para a origem da filosofia, como Moisés para o judaísmo e Jesus Cristo para o cristianismo. Na linguagem de Derrida (2001, p. 73), poder-se-ia dizer que ele é: "O primeiro arquivista", aquele que "institui o arquivo como deve ser, isto é, não apenas exibindo o documento, mas estabelecendo-o. Ele o lê, interpreta e classifica".

A forma como Sócrates filosofou representa uma guinada na compreensão da filosofia no mundo antigo, abrindo um novo caminho para relação entre filosofia e educação. Até então os filósofos eram naturalistas, isto é, se preocupavam em entender os desígnios da physis, procurando deslindar o sentido mais profundo da ordem cósmica que subjaz a todas as coisas ou fenômenos. Sócrates coloca no centro da preocupação com o filosofar o aspecto humano - a feição antropocêntrica, entendendo que a ordenação é fruto de um equilíbrio conquistado pela reflexão sobre si mesmo.

Do mesmo modo que Moisés teve a proteção da nuvem divina diante das investidas dos israelitas, Sócrates dizia ter um daímon interior (conselho divino) que o auxiliava a se livrar das agruras do destino. Ele se dizia iluminado por intermédio do Oráculo de Delfos, lido por uma pitonisa, conforme descreve Platão na obra "Apologia de Sócrates". Porém, foi levado aos tribunais pela primeira e única vez quando tinha mais de 70 anos, acusado de subverter a juventude com discursos sofísticos. A sua morte não foi provocada pelos discípulos, e sim pelos que o detratavam e perseguiam. Com o seu fim, o arquivo sobreviveu no testemunho de Platão e Xenofontes, que deram garantia de continuidade ao seu legado na escritura de diversas obras. A corrosão do arquivo, enquanto verdade 
material, abre a filosofia para a sua verdade histórica, principalmente ficcional. O discurso que se institui posteriormente é uma forma de redenção do Sócrates original, a sua reencenação. E isso ocorre não sem contestações, silêncios e abandonos, pois Aristófanes, em sua comédia As nuvens, e mais tarde Friedrich Nietzsche, em "A origem da tragédia no espírito da música", por exemplo, se levantam bravamente contra a perpetuação do seu culto.

Se a psicanálise foi acusada de ser "um judaísmo sem Deus" (DERRIDA, 2001, p. 65), pode ser dito o mesmo da filosofia, ou seja, que ela é, também, uma religião sem Deus? Há que se levar em consideração que a diferença entre filosofia e religião nem sempre é muito evidente, pois boa parte do seu desenvolvimento se deu em íntima conexão com a teologia e o convívio das igrejas. Apesar de o pai fundador da crença filosófica (Sócrates) ter afirmado que recebeu sua incumbência dos deuses, não podemos ir tão longe nessa afirmação, já que a filosofia passou por algumas etapas posteriores de aderência ao discurso da secularização. Mas sem dúvida que existem mais semelhanças do que diferenças entre os discursos da psicanálise e da filosofia pensadas na perspectiva do mal de arquivo.

\section{Inventivas para a filosofia e a educação}

Depois de apresentar algumas aproximações entre a psicanálise e a filosofia da educação a respeito do problema do mal de arquivo, vamos retomar a pergunta apresentada no início deste texto para projetar ou abrir algumas portas para o futuro da relação entre filosofia e educação. Ela indaga se um dos grandes problemas da filosofia da educação não se refere ao desejo de volta à sua origem (à sua casa) na filosofia.

A necessidade de retornar a um passado idílico não é de todo desprovida de fundamento, desde que não seja uma nostalgia do ser absoluto. Não raro nos deparamos com vários problemas de toda ordem no manejo de conceitos, referência a autoridades no assunto e às suas genealogias e estruturas de pensamento no campo da educação, que instigam o saudosismo. Um dos graves problemas pode ser evidenciado na docência, devido aos mestres estarem excessivamente "pedagogizados", segundo a expressão utilizada por Pereira (2008, p. 174). Esses mestres transitam pela vulgarização e simplificação de correntes psicológicas como o humanismo x comportamentalismo, oferecendo um aprofundamento de tais temas na linha de livros de autoajuda ou de reportagens de bancas de revistas e jornais. Além disso, tal simplificação abrange ainda os 
estudos da psicanálise na educação, por conta das promessas não cumpridas pela psicologia de explicar o domínio do outro, isto é, "tecnologias do cuidado, a racionalidade comportamental e o saber sobre o outro" (PEREIRA, 2008, p. 175). Como esse ideário não se cumpriu, abrem-se lacunas para a inserção do saber da psicanálise com o mesmo objetivo, bem como para o incremento da abertura de cursos de especialização em psicopedagogia. Além disso, salienta ainda o autor: "As teorias pedagógicas, ao contribuírem para colocar em suspensão parte da autoridade do mestre, parecem tê-lo abandonado, como também seus discípulos, à sua própria sorte" (PEREIRA, 2008, p. 168). Ou seja, estamos revivendo um quadro que contribui para o mal-estar docente e que abre para a violência insurgente nas escolas, uma vez que o afrouxamento de regras de certas pedagogias pode ter colaborado para esse processo. ${ }^{5}$ Outra questão bastante comum é o problema da exclusão periódica do ensino de filosofia das escolas e seu encurtamento no campo das licenciaturas, ora incriminada de estar a serviço da doutrinação dos alunos, por parte da sociedade e do sistema, ora sendo acusada pelas outras áreas do conhecimento de não ter finalidade prática.

Ora, Freud também lutou contra a supersimplificação dos saberes no campo da psicanálise. Ao buscar fundamentos na obra freudiana para criticar os códigos de interpretação do inconsciente, baseados em esquemas fechados que atribuíam sentidos apriorísticos aos símbolos evocados nos sonhos, Derrida (1971, p. 197) assevera: "Tanto quanto a generalidade e a rigidez do código, este limite reside no fato de haver uma excessiva preocupação com conteúdos, uma reduzida preocupação com relações, situações, funcionamento e diferenças". A situação descrita pelo filósofo francês não deixa de ter proximidade pela facilitação excessiva de tratamento de questões que dependem de uma leitura que se caracteriza pela sua dimensão contextual, diferenciada e caso a caso.

Não seria essa outra reencenação do mal de arquivo, agora lido metaforicamente na relação entre filosofia e educação, a saber, a acusação de corrupção da juventude foi a mesma que pesou sobre Sócrates, levando à sua condenação e morte, o parricídio, portanto? De outra parte, fica a dúvida se os saberes surgidos integradamente, e somente depois desmembrando-se, lidariam

5 Segundo o "Atlas da violência 2018”, que traz o índice de homicídios praticados no Brasil por regiões, o índice de homicídios é 30 vezes mais alto do que a taxa na Europa (CERQUEIRA, 2018). E, segundo pesquisa divulgada pela Organização para a Cooperação e Desenvolvimento Econômico (OCDE), o Brasil é campeão mundial de violência contra o professor (GOMES, 2015). Aqui caberia um aprofundamento filosófico da relação entre crise de autoridade e violência nas escolas, uma vez que, segundo Aquino $(1998$, p. 8) duas abordagens predominam nesse aspecto no campo da educação: "uma de cunho nitidamente sociologizante, e outra de matiz mais clínico-psicologizante". 
como uma culpa de mesmo tipo daquela presente na cultura e na diáspora, a de não poderem enfrentar sua própria natureza originária, tendo por isso constantemente de ocultá-la. Diante dessas questões, e do quadro problemático em que se encontra a educação, não seria o caso de a filosofia da educação aderir à estratégia freudiana de derrubada das fronteiras para acabar com a dicotomia do nós e eles, apagando do mesmo modo a diferença entre as oposições binárias que se colocam? Em outras palavras, seria viável procurar uma identificação mínima com o agressor, mostrando por dentro a sua incongruência?

É claro que isso não implicaria, de alguma maneira, assumir a "pedagogização do mestre", o discurso das habilidades e competências, a pedagogia com foco no aluno e com as suas excessivas "dinâmicas de grupo", isto é, assumir a pobreza da experiência filosófica como constitutiva do saber pedagógico. Essas enunciações esquecem ou deixam de contemplar uma das lições da reflexão de arquivo proposta por Freud-Derrida, a saber, que há uma tendência à reedição da violência originária, que ocasionou o arquivo e o mal de arquivo. Além disso, essa aderência esquece de perceber que, no caso de Freud, havia um outro sentido em questão, pois se tratava de mostrar que a acusação contra os judeus era falsa, uma vez que eles na verdade tinham outra descendência. Em relação à filosofia, a morte de Sócrates é reeditada simbolicamente nessas situações, ora pela sua exclusão pura e simples das estruturas curriculares dos cursos, ou seja, pelo apagamento do seu arquivo nas disciplinas, ora pelo silenciamento de suas propostas pela adesão à onda neoconservadora de anti-intectualismo.

Diferente disso é buscar inspiração no próprio testemunho de Sócrates, que cultivava um tipo de saber que não era exatamente o mesmo dos sofistas, por exemplo. Segundo Jaeger (1995), tanto Xenofontes como Platão descrevem os diálogos socráticos em geral ligados aos ambientes de banquetes ou de ginásios, não por acaso. Os sofistas ensinavam nos locais seletos como palcos, casas particulares ou aulas improvisadas e a sua narrativa era voltada para os cidadãos abastados da cidade. Por sua vez, Sócrates cultivava um diálogo improvisado em locais públicos, havia uma dimensão política no seu trato filosófico que não era a busca da submissão de discípulos, mas buscava compartilhar as suas dúvidas com amigos, junto a esses outros locais: "Surgiu assim uma ginástica do pensamento que logo teve tantos partidários e admiradores como a do corpo, $\mathrm{e}$ não tardou a ser reconhecida como o que esta já vinha sendo havia muito: como uma nova forma de paidéia" (JAEGER, 1995, p. 523). Nesse caso podemos arriscar a dizer que há uma proximidade com a estratégia freudiana, pois em oposição à vulgarização sofrida pelos judeus realizada pelos nazistas, que os acusavam de degenerar a raça, Freud mostrou que Moisés advinha de uma outra 
estirpe, bem superior, ou seja, que Moisés não era apenas o "líder político dos judeus estabelecidos no Egito, mas também seu legislador e educador" (FREUD, 2018, p. 49). Portanto, assim como na tradição judaica, na origem da filosofia está o combate à vulgarização do saber e a defesa da identificação pelo alto.

\section{Conclusões}

O texto procura discutir os temas do arquivo e mal de arquivo sob a ótica da crítica de Derrida a Freud e alguns de seus intérpretes. Busca desconstruir algumas das teses básicas freudianas, e reafirmar outras, com vistas ao incremento do diálogo entre filosofia e educação. Após algumas inventivas, no sentido de abrir possibilidades futuras a partir da retomada da hermenêutica das tradições do termo arquivo, poderíamos, propor e perguntar o seguinte: a) Com vistas às acusações feitas, o gesto freudiano de reencenar a morte do pai pelo bando originário poderia servir como um movimento autocrítico da própria filosofia da educação em relaão à sua tradição? b) Sem abandonar a trincheira crítica, e com base em Derrida e Birman, repetir o gesto freudiano é suficiente; que consequências viriam daí?

A desconstrução da metafísica é um trabalho que vem sendo realizado por diversos movimentos da filosofia contemporânea, da hermenêutica e (neo)pragmatismo à teoria crítica, pela fenomenologia da subjetividade ao movimento da virada linguística e da analítica, entre outros; procuram deslindar o estreitamento da trajetória do logocentrismo ocidental que desembocou no culto da razão técnica. A filosofia e a educação contemporâneas procuram mostrar os constrangimentos a que leva esse tipo de raciocínio no campo dos estudos da sexualidade, de gênero, crença e etnia, por exemplo. E o quanto estamos submetidos a esquemas de compreensão que limitam ou robotizam o nosso pensamento, tolhendo a criatividade, a originalidade e a ousadia. Por isso é importante repensar um conceito que deu suporte historicamente a essa racionalidade, como o de arquivo. A crítica derridiana procura abrir essa noção para situações novas e imprevisíveis que possam resguardar a possibilidade do que ele chama em seu livro de "perturbação do arquivo" (DERRIDA, 2001, p. 118).

O retorno ao primitivo faz aflorar a consciência, e, portanto, traz o recalcado de volta para o nível literal da escritura, possibilitando o acontecimento da compreensão que pode auxiliar a desmobilizar a repetição que se instaurou no arquivo. Na medida em que percebemos determinado campo, ou área do conhecimento, estar prisioneiro da pulsão de morte (do mal de arquivo), pode 
então se distanciar da sua feérica tradição, libertando-se do poder inconsciente que o governa. Essa é uma iniciativa que tem impacto na tradição da metafísica e, por conseguinte, nos debates sobre os rumos da filosofia e da educação, na medida em que vemos retornar bandeiras na sociedade brasileira atualmente que defendem pautas represadas na história. Entre elas, podemos citar a insistência com a volta da disciplina de moral e cívica, cursos e bibliotecas expurgados do veneno marxista, libertação da doutrinação comunista, limitação aos estudos de gênero e sexualidade em sala de aula. Certamente é contra esse fechamento do arquivo no seu conceito clássico, voltado somente em direção à memória da repetição e da culpa do recalque, que levou Derrida a esboçar a sua interpretação do tema. Não é essa abertura que ele pensava ao propor a sua noção de mal de arquivo, mas podemos interpretar esse fechamento pelo seu avesso, portanto.

A morte de Sócrates está sendo reeditada nessas pautas, pois a sua defesa era em prol de um saber da "exortação (protreptikos) e a indagação (elenchos)", sendo que ambas eram figuradas em forma de perguntas (JAEGER, 1995, p. 525). Por isso Sócrates é definido por Jaeger como "um arquivo" com as seguintes características: "Era o grande conhecedor de homens, cujas perguntas certeiras serviam de pedra de toque para descobrir todos os talentos e todas as forças latentes, e a quem iam pedir conselho, para a educação dos filhos, os cidadãos mais respeitados" (JAEGER, 1995, p. 522). Se os pais buscavam os conselhos de Sócrates para bem educar seus filhos é porque viam nele um arquivo aberto e generoso com o futuro. $\mathrm{O}$ que o filósofo ateniense tem em comum com o profeta Moisés e Jesus Cristo é que eles, cada um a seu tempo, e a sua maneira, não somente serviram a tânatos, destruindo velhos arquivos. Mas, retornando ao passado, também não ficaram presos na compulsão da repetição, e sim foram capazes de editar novos arquivos pela força de eros. Há, portanto, uma diferença homérica entre um saber pedagógico que indaga e levanta objeções e um outro que simplesmente repete ou reafirma o reprimido, um saber que referenda crenças normalmente aceitas e outro que as põe em suspensão. Fazer o "exorcismo" ou a terapia desses fantasmas é um desafio conjunto para a psicanálise, filosofia e educação e, ainda, ao ensino da religião para ir além de uma luta inglória com o presente, que hipostasia a compulsiva e necrófila reedição do passado. 


\section{REFERÊNCIAS}

ALMEIDA, Rogério Miranda de. Eros e Tânatos: a vida, a morte, o desejo. São Paulo: Loyola, 2007.

ARISTÓFANES. As nuvens. Uma comédia grega. Rio de Janeiro: Zahar, 2014.

AQUINO, Júlio Groppa. A violência escolar e a crise da autoridade docente. Cadernos Cedes, Campinas, ano 19, n. 47, p. 7-19, dez. 1998.

ASSMANN, Jan. Moses the Egyptian: The memory of Egypt in western monotheism. Cambridge: Harvard University Press, 1998.

BERNSTEIN, Richard J. Freud e o legado de Moisés. Rio de Janeiro: Imago, 2000.

BIRMAN, Joel. Arquivo e Mal de Arquivo: Uma leitura de Derrida sobre Freud. Natureza humana, v. 10, n.1, p. 105-128, jan/jun, 2008.

CERQUEIRA, Daniel (coord.). Atlas da violência 2018. Rio de Janeiro: IPEA; FSBSP, 2018. Disponível em: http://www.ipea.gov.br/portal/images/stories/PDFs/relatorio institucional/180604_atlas_da_violencia_2018.pdf. Acesso: 16 fev. 2019.

DERRIDA, Jacques. A escritura e a diferença. São Paulo: Perspectiva, 1971.

DERRIDA, Jacques. Derrida caça os fantasmas de Marx. [Entrevista concedida a] Betty Milan. Folha de São Paulo, Caderno MAIS, São Paulo, 26 jun. 1994. Disponível em: https://www1.folha.uol.com.br/fsp/1994/6/26/mais!/24.html. Acesso: 13 fev. 2019.

DERRIDA, Jacques. Mal de arquivo: uma impressão freudiana. Rio de Janeiro: Relume Dumará, 2001.

FREUD, Sigmund. Mal-estar na civilização. Tradução de Jayme Salomão. Rio de Janeiro: Imago, 1980. (Edição Standart Brasileira das Obras Completas, v. 21).

FREUD, Sigmund. Uma nota sobre o 'Bloco Mágico'. Tradução de Jayme Salomão (org.). Rio de Janeiro: Imago, 1996. p. 255-259. (Edição Standard Brasileira das Obras Psicológicas completas de Sigmund Freud, v. 19).

FREUD, Sigmund. O Moisés, de Michelangelo. In: Arte, literatura e os artistas das obras incompletas de Sigmundo Freud. Tradução de Ernani Chaves. Belo Horizonte: Autêntica, 2015. p. 183-219.

FREUD, Sigmund. O homem Moisés e a religião monoteísta: Três ensaios. Porto Alegre: L\&PM, 2018.

GOMES, Luiz Flávio. Brasil: campeão mundial de violência contra professores. [S.l.]: jusbrasil, 2015. Disponível em: https://professorlfg.jusbrasil.com.br/artigos/136798228/ brasil-campeao-mundial-na-violencia-contra-professores. Acesso: 16 fev. 2019.

JAEGER, Werner. Paidéia: a formação do homem grego. São Paulo: Martins Fontes, 1995. 
MENESES, Ramiro Délio Borges de. A desconstrução em Jacques Derrida: o que é e o que não é pela estratégia. Universitas Philosophica 60; Bogotá, año 30, p. 177-204, enero/jun. 2013.

PEREIRA, Marcelo Ricardo. A impostura do mestre. Belo Horizonte: Argvmentvm, 2008.

RICOEUR, Paul. Freud: una interpretación de la cultura. Barcelona: Siglo XXI, 1990. Disponível em: https://mercaba.org/SANLUIS/Filosofia/autores/ Contempor\%C3\%A1nea/Ricoeur/Freud,\%20una\%20interpretaci\%C3\%B3n\%20de\%20 la\%20cultura.pdf. Acesso em: 12 fev. 2019.

SOLIS, Dirce Eleonora Nigro. Tela desconstrucionista: arquivo e mal de arquivo a partir de Jacques Derrida. Rev. Filos. Aurora, Curitiba, v. 26, n. 38, p. 373-389, jan./jun. 2014.

YERUSHALMI, Yosef Hayim. O Moisés de Freud: Judaísmo terminável e interminável. Rio de Janeiro: Imago, 1992.

Texto recebido em 12/05/2020.

Texto aprovado em $27 / 02 / 2021$. 